\title{
IDENTIFIKASI JENIS-JENIS PANDANACEAE DI PULAU PEPAYA PADA KAWASAN TAMAN NASIONAL TELUK CENDERAWASIH \\ (Identification of Pandanaceae Types in Pepaya Island in The National Park Areas of Teluk Cenderawasih)
}

\author{
ZETH PARINDING \\ Balai Besar Taman Nasional Teluk Cenderawasih \\ e-mail: zethparksdae@gmail.com
}

\begin{abstract}
ABSTRAK
Diversitas pandanus di Papua masih banyak yang belum diketahui, walaupun cukup banyak yang sudah diidentifikasikan. Pandanus pada kawasan Taman Nasional Teluk Cenderawasih, sampai saat ini belum didokumentasikan dengan baik, sehingga diversitas pada pulau dan pesisirnya perlu diidentifikasikan kembali. Metode yang digunakan adalah metode deskriptif dengan teknik survei lapang dan wawancara semi struktural serta studi literatur. Variabel yang diamati dalam penelitian ini adalah jenis-jenis buah pandan, yang tampak saat ditemukan atau pada Herbarium Pusat Keanekaragaman Hayati (PPKH) Universitas Papua Manokwari dengan obyek utama yaitu jenisjenis Pandanus sp. di pulau Pepaya pada kawasan Taman Nasional Teluk Cenderawasih. Jenisjenis pandanus di Pulau Pepaya pada kawasan Taman Nasional Teluk Cenderawasih ditemukan sebanyak 3 jenis, yaitu: Pandanus tectorius, Pandanus odoratissimus, dan Pandanus polycephalus (yang berbeda).
\end{abstract}

Kata Kunci: Jenis-Jenis Pandanus, Pulau Papaya,Taman Nasional Teluk Cenderawasih

\section{PENDAHULUAN}

Kawasan Taman Nasional Teluk Cenderawasih (TNTC) terletak pada dua Propinsi, yaitu: Provinsi Papua dan Provinsi Papua Barat, dengan 4 Kabupaten, yaitu: Manokwari, Nabire, Teluk Wondama dan Manokwari Selatan. Adapun luasan kawasan Taman Nasional Teluk Cenderawasih seluas 1.453.500 ha. Kawasan TNTC ini juga merupakan bagian dari Bentang Laut Kepala BurungBLKB (Seascape Head Birds-BHS). Kawasan TNTC ini memiliki banyak sekali diversitas tumbuhan dan satwa liar, meskipun sudah banyak yang diteliti. Namun hal ini diduga masih banyak akan ditemukan varietas dan jenis yang baru baik di pesisir dan lautnya di pulau besar maupun di pulau-pulau kecilnya.

Pandanus ini merupakan tumbuhan monokotil. Genus Pandanus merupakan salah satu dari famili Pandanaceae, yang lainnya seperti Freycinetia, Sararanga, Martellidendron, dan Benstonea (Stone, 1982), yang mana diperkirakan mencapai 700 jenis (Marpaung et al, 2013), bahkan 900 jenis. Saat ini jenis-jenis pandanus dari famili Pandanaceae masih sedikit diketahui jenisnya di kawasan TNTC. Iyai \& Patisellano (2006), Pulau Pepaya ditumbuhi jenis-jenis Pandanus, yang mana belum diketahui spesiesnya, sebagai habitat biawak (Varanus indicus). Oleh karena itu, perlu penelitian untuk menemukan potensi jenis-jenis pandanus, meskipun kemanfaatan dari jenis-jenis pandanus tersebut sering dimanfaatkan masyarakat adat dan lokal setempat. Adapun Pulau Pepaya merupakan salah satu pulau yang memiliki luasan hanya 2,42 ha, ternyata memiliki keanekaragaman hayati yang cukup tinggi dibandingkan pulau-pulau yang berada di kawasan TNTC. Pulau Pepaya berdekatan dengan pulau Nuburi dan pulau Nutabari. Dengan demikian perlu adanya penelitian untuk mengidentifikasikan jenis-jenis pandanus di Pulau Pepaya pada kawasan Taman Nasional Teluk Cenderawasih

Penelitian ini dilakukan pada salah satu kawasan pulau kecil yang berada pada Bentang Laut Kepala Burung-BLKB (Seascape Head Birds-BHS) Papua di Provinsi Papua, yakni: pulau Pepaya di Kabupaten Nabire pada Taman Nasional Teluk Cenderawasih. Adapun tujuan penulisan 
ini adalah untuk mendeskripsikan dan mengidentifikasi jenis-jenis pandanaceae di pulau Pepaya pada kawasan Taman Nasional Teluk Cenderawasih.

\section{METODE PENELITIAN}

Pengamatan di lakukan pada pulau Pepaya di Kabupaten Nabire, Papua. Pulau Pepaya, secara geografis terletak pada $03^{\circ} 11^{\prime} 33,7^{\prime}$ LS dan $135^{\circ} 04^{\prime} 52,6^{\prime \prime}$ BT dengan luasannya 2,42 Ha. Pulau ini juga berada pada Bentang Laut Kepala Burung-BLKB (Seascape Head Birds-BHS) Papua di Provinsi Papua selama seminggu pada bulan Maret 2021. Penelitian dilakukan pada saat jenis-jenis pandan diduga telah berbuah, untuk dapat diidentifikasikan jenis-jenis buah yang dihasilkan. Selanjutnya difoto yang belum pernah ditemukan buah sebelumnya. Metode yang digunakan adalah metode deskriptif dengan teknik survei lapang dan wawancara semistruktural serta studi literatur. Variabel yang diamati dalam penelitian ini adalah jenis-jenis buah pandan, yang tampak saat ditemukan atau pada Herbarium Pusat Keanekaragaman Hayati (PPKH) Universitas Papua Manokwari dengan obyek utama yaitu jenis-jenis Pandanus sp. di pulau Pepaya pada kawasan Taman Nasional Teluk Cenderawasih. Selanjutnya data yang dikumpulkan dianalisis dan disajikan dalam bentuk tabel dan gambar. Dalam melakukan penelitian memerlukan alat-alat dan bahan penelitian. Alat-alat penelitian yang digunakan, antara lain: speedboat, peta lokasi penelitian, literasi identifikasi pandanaceae, polyethilen, kamera, parang, head splashligt, personal use, senter besar,. Sedangkan bahan penelitian berupa alkohol dan kertas koran.

Berdasarkan data jenis-jenis pandanceae akan berbuah cenderung di bulan Januari sampai dengan bulan Mei, sehingga data diambil hanya pada bulan Maret disaat banyak jenis pandanaceae berbuah. Hal ini dilakukan sebagai informasi data awal, yang mana buah pandanaceae banyak ditemukan berbuah baik yang sudah matang dengan berbagai warna seperti merah atau kuning maupun masih terbungkus atau sudah nampak buah dan masih berwarna hijau.atau putih.Metode penelitian menggunakan metode deskriktif. Identifikasi jenis-jenis pandanaceae dilakukan dengan membandingkan jenis-jenis pandanaceae yang telah ditemukan sebelum. Selain itu, Studi literatur terhadap jenis-jenis yang ditemukan, dan bertanya kepada pakar jenis pandanaceae. Selanjutnya jenis yang agak berbeda dibanding satu sama lainnya. Identifikasi ini dilakukan untuk mendeskripsikan jenis-jenis pandanaceae yang berada di pulau Papaya pada kawasan Taman Nasional Teluk Cenderawasih, yang mana merupakan bagian dari Bentangan Laut Kepala Burung Papua.

\section{HASIL DAN PEMBAHASAN}

\section{Hasil}

Berdasarkan hasil observasi di pulau Pepaya pada kawasan Taman Nasional Teluk Cenderawasih, Kabupaten Nabire, Provinsi Papua, ditemukan 3 jenis pandanus. Ketiga jenis pandanus pada pulau Pepaya, yang ditemukan adalah jenis Pandanus tectorius, Pandanus odoratissimus L.f., dan Pandanus Polycephalus (yang berbeda) disajikan pada Tabel 1.

Tabel 1. Jenis-jenis pandanus di pulau Papaya pada kawasan Taman Nasional Teluk Cenderawasih

\begin{tabular}{|r|c|c|l|l|}
\hline No & Sub Famili & Marga & \multicolumn{1}{|c|}{ Spesies } & Nama Lokal \\
\hline 1. & Pandanaceae & Pandanus & $\begin{array}{l}\text { Pandanus polycephalus Lam (diduga } \\
\text { Var/New) }\end{array}$ & Pandan \\
\hline 2. & Pandanaceae & Pandanus & Pandanus odoratissimus L.f. & Pandan tikar/laut \\
\hline 3. & Pandanaceae & Pandanus & Pandanus tectorius Parkinson & Pandan duri/laut \\
\hline
\end{tabular}




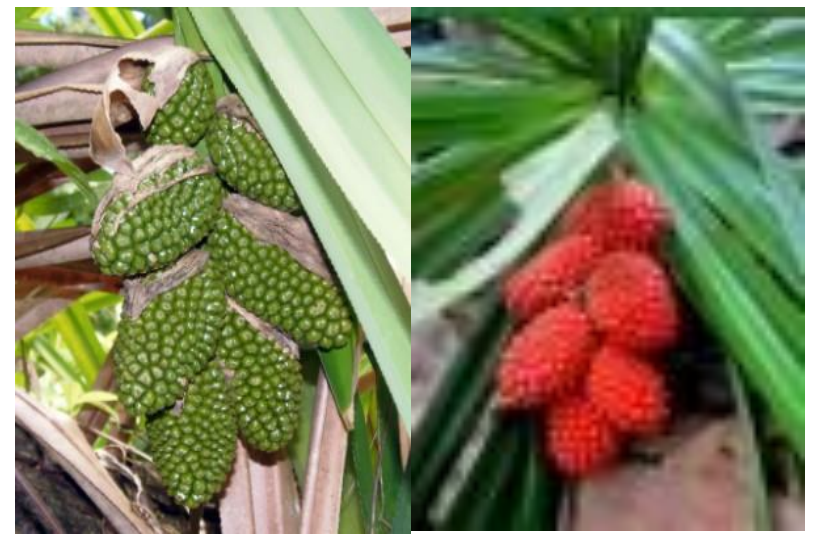

(a) (b)

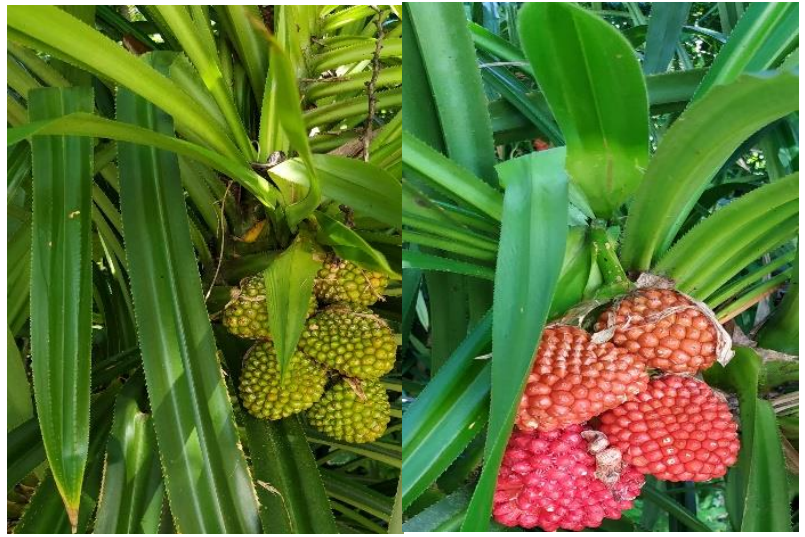

(c)

Gambar 1. Pandanus polycephalus Lam (a,b dari Internet), sedangkan (c, d dari pengamatan diduga varietas atau jenis baru)

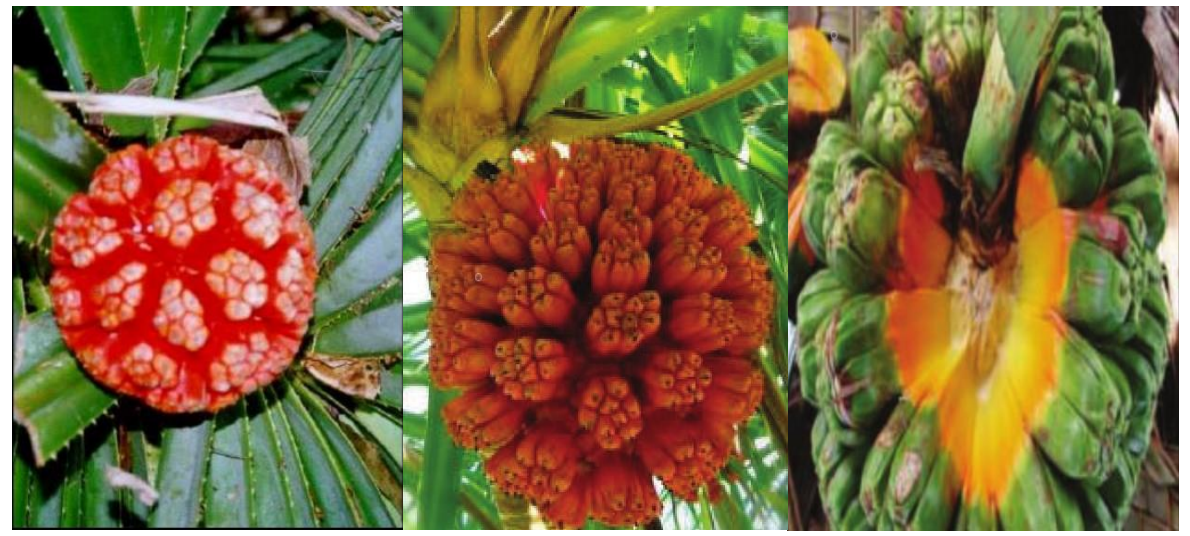

Gambar 2. Pandanus odoratissimus L.f. (a,b dari Internet)

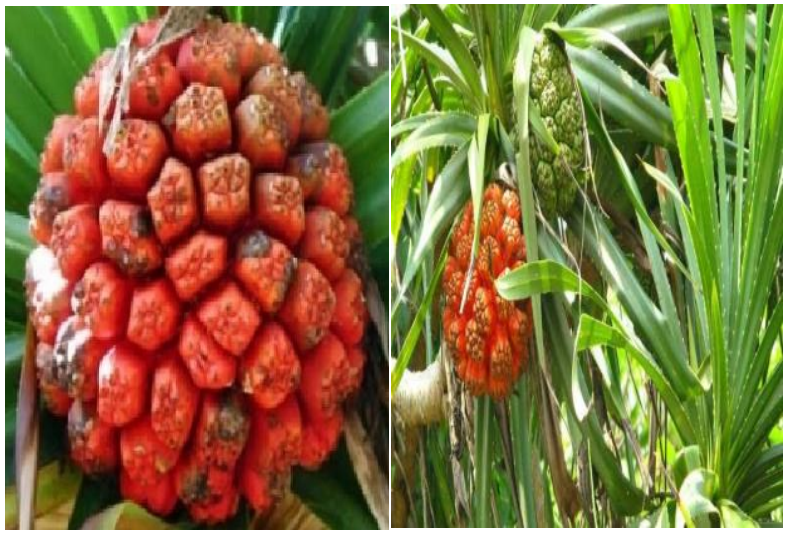

Gambar 3. Pandanus tectorius Parkinson (a,b dari Internet)

\section{Pembahasan}

Genus terbesar dari famili Pandanaceae adalah genus Pandanus (Stone, 1982). Genus pandanus yang tercatat sekarang kurang lebih 500 s/d 700 jenis, Namun jenis-jenis pandanus di Tanah Papua belum banyak dieksplorasi, maka diperkirakan dapat melebihi dari 900 jenis. Diperkirakan jenis-jenis pandanus baru sekitar 66 jenis dengan proporsi endemisme. Endemisme yang tinggi baik pada spesies maupun tingkatan taksonominya.

Jenis-jenis pandanus oleh orang Papua yang beragam suku, yakni lebih dari 250 suku bangsa, bahkan dapat melebih 400 s/d 700 suku, yang mana bermukim dari pulau kecil, pantai 
sampai ke pegunungan. Mereka tersebut memiliki cara yang bahkan berbeda satu sama lainnya dalam memanfaatklan berbagai jenis hewan dan tumbuhan, yang mana juga untuk jenis pandanus (Zebua et al., 2009), untuk masyarakat kampung Papuma di Kepulauan Yapen Papua memanfaatkan serat akar Pandanus tectorius sebagai alat penangkap ikan dan daunnya dimanfaatkan sebagai bahan tikar. Bentuk dan fungsi tikar yang dibuat, seperti: a) tikar lipat, untuk pengalas tempat tidur, dan pelindung barang bawaan baik saat di laut maupun saat hari hujan; b) tikar gulung, untuk digunakan pengalas tempat tidur, dan juga untuk menutupi tubuh saat mandi uap (ungkep), saat mandi uap dari air panas; c) tikar payung, untuk untuk menutup tubuh saat hujan dan panas, dan juga barang bawaan saat hujan. Sedangkan Susiarti et al. (2013), Rahayu (2008), Rahayu et al (2008), \& Heyne (1987), Pandanus sebagai jenis dengan kelompok tumbuhannya memiliki manfaat bagi kehidupan masyarakat, antara lain: bahan makanan (Purwanto \& Munaroh, 2010), pewangi, zat pewarna, bahan anyaman, atap, tikar, obat-obatan, tanaman hias, obat-obatan, akar tunjangnya untuk tali ikan, dan lain-lain.

Ketiga jenis yang ditemukan ini, sebelumnya belum dapat diketahui secara pasti jenisjenisnya dikarenakan belum berbuah (Iyai \& Patisellano, 2006). Ketiga jenis pandanus ini juga tidak berbuah secara bersamaan, sehingga hal ini menyebabkan kesulitan dalam mengidentifikasikan perbedaan di antara jenis-jenis pandanus tersebut.

Duwiri et al. (2010), Kameray (2013), jenis Pandanus tectorius lebih cenderung berada pada pasir yang berkarang, Pandanus polycephalus berada dibelakang tumbuhan besar dan tinggi termasuk dekat pohon kelapa dengan pasir yang agak lembab. Sedangkan Adkar \& Bhaskar (2014), jenis Pandanus odoratissimus berada di antara tempat tumbuh dari kedua jenis tersebut.

\section{Pandanus tectorius}

Pandanus tectorius dapat ditemukan pada daerah pantai berupa daratan yang relatif kering dengan terkstur tanah berpasir, namun masih terpengaruh pasang surut air laut. perawakan atau keragaannya tumbuhannya besar. Permukaan batang ada lentilsel. Bentuk daun berupa bangun lidah. Daunnya memiliki duri membalik (recurved spines), sedangkan duri daunnya berada pada tepi daun (margin) berduri dan berwarna agak terang. Selain itu juga duri membalik terdapat pada permukaan bawah daun dan berwarna terang.

Perbungaan terletak di ujung batang (terminal). Tidak ditemukan perbedaan antara mahkota (corolla) dan kelopak (calyx) bunga atau bunga pandan, perhiasan bunga hanya tersusun (perianth). Selain itu jumlah dari benang sarinya sangat banyak.

Permukaan atas daun berwarna hijau mengkilat, dan buahnya majemuk bulat dengan satu tandan tanpa bercabang. Sedangkan permukaan buah (phalange) rata (tidak menonjol).

\section{Pandanus odoratissimus}

Pandanus odoratissimus dapat ditemukan pada daerah pantai berupa daratan yang relatif kering dengan terkstur tanah berpasir, namun masih terpengaruh pasang surut air laut. perawakan atau keragaannya tumbuhannya besar. Permukaan batang ada lentilsel. Bentuk daun berupa bangun lidah. Daunnya memiliki duri membalik (recurved spines), sedangkan duri daunnya berada pada tepi daun (margin) berduri dan berwarna agak terang. Selain itu juga duri membalik terdapat pada permukaan bawah daun dan berwarna terang.

Perbungaan terletak di ujung batang (terminal). Tidak ditemukan perbedaan antara mahkota (corolla) dan kelopak (calyx) bunga atau bunga pandan, perhiasan bunga hanya tersusun (perianth). Selain itu jumlah dari benang sarinya sangat banyak. Permukaan atas daun berwarna hijau mengkilat, dan buahnya majemuk bulat dengan satu tandan tanpa bercabang. Sedangkan permukaan buah (phalange) menonjol. 


\section{Pandanus polycephalus}

Pandanus tectorius dapat ditemukan pada daerah pantai berupa daratan yang relatif kering dengan terkstur tanah berpasir, namun masih terpengaruh pasang surut air laut. perawakan atau keragaannya tumbuhannya besar. Permukaan batang ada lentilsel. Bentuk daun berupa bangun lidah. Daunnya memiliki duri membalik (recurved spines), sedangkan duri daunnya berada pada tepi daun (margin) berduri dan berwarna agak terang. Selain itu juga duri membalik terdapat pada permukaan bawah daun dan berwarna terang.

Perbungaan terletak di ujung batang (terminal). Tidak ditemukan perbedaan antara mahkota (corolla) dan kelopak (calyx) bunga atau bunga pandan, perhiasan bunga hanya tersusun (perianth). Selain itu jumlah dari benang sarinya sangat banyak. Permukaan atas daun berwarna hijau mengkilat, dan buahnya majemuk bulat dengan satu tandan bercabang 7 buah. Sedangkan permukaan buah (phalange) lebih menonjol dan tajam.

Jenis Pandanus polycephalus, yang ditemukan diduga merupakan varietas atau jenis yang berbeda. Karena buah yang dihasilkan dalam satu tandan sebanyak 5 buah (seperti sisir pisang), dan juga permukaan buah (phalange) lebih menonjol dan tidak tajam (agak tumpul). Menurut beberapa informan dan juga informasi masyarakat, bahwa pandanus yang ada di pulau Pepaya banyak manfaat untuk sebagai bahan makanan, obat, dan atap rumah/sirap. Setelah perkembangan modern, atap rumah/sirap banyak digantikan dengan terpal atau atap seng. Jenis pandanus ini sangat bermanfaat dari akar, batang, daun, dan buahnya.

Pulau ini sering dikunjungi oleh masyarakat atau nelayan dalam perjalanan melaut, apabila cuaca sedang tidak bersahabat. Selanjutnya mereka akan tinggal sebentar dengan mendirikan bivak, dengan memanfaatkan sumber daya yang ada di pulau Pepaya tersebut. Selain itu untuk beberapa tahun belakangan ini, ternyata pada ujung tanjung pulau Pepaya ini, signal telekomunikasi dapat diperoleh, walaupun hanya untuk telepon dengan jaringan yang tidak terlalu bagus.

Dengan demikian, strategis pengelolaan jenis-jenis pandanus di pulau Pepaya pada kawasan TNTC, antara lain: 1. Mendayagunakan jenis-jenis tumbuhan pandanus secara arif dan berkelanjutan; 2. Mencegah perburuan daging penyu dan telurnya, yang menyebabkan jarang ditemukan penyu bertelur; 3. pendataan kembali atau pemetaan partisipatif marga pemilik hak ulayat dan juga pemanfaat dari tumbuhan pandanus tersebut, dan 4. Tempat kunjungan masyarakat atau nelayan setempat, untuk persinggahan memanfaatkan jaringan signal telekomunikasi (telepon), yang mana ada di sekitar ujung pulau tersebut.

\section{KESIMPULAN}

Banyak varietas dan jenis pandanus, yang dapat diduga sebagai temuan yang perlu dieksplorasi secara mendalam dan terstruktur dengan baik untuk jenis-jenis pandanus yang ada di kawasan Taman Nasional Teluk Cenderawasih. Pandanus pada pulau Pepaya pada kawasan Taman Nasional Teluk Cenderawasih berhasil ditemukan sebanyak 3 jenis, yaitu: Pandanus tectorius Parkinson, Pandanus odoratissimus L.f., dan Pandanus Polycephalus Lam (diduga berbeda sebagai jenis dan varietas baru). Dengan ditemukan ketiga jenis pandanus ini memberikan kontribusi kekayaan diversitas pandanus.

\section{DAFTAR PUSTAKA}

Adkar PP \& Bhaskar VH. 2014. Reviw Article: Pandanus odoratissimus (Kewda): A Review on Ethnopharmacology, Phytochemistry, and Nutritional Aspects. Hindawi Article ID 120895. http:// dx.doi.org/10.1155/2014/120895.

Duwiri F, Nunaki JH, \& Pattiselano F. 2010. Identifikasi Jenis-Jenis Pakan Alami Kuskus (Phalangeridae) di pulau Hariti Distrik Napan Weinami Kabupaten Nabire. Jurnal Natural. 21 
Januari 2019. DOI: 10.30862/jn.v9i1.775. https://www.researchgate.net/publication/ 423752855.

Heyne K. 1987. Tumbuhan Berkayu Indonesia. Badan Penelitian dan Pengembangan Kehutanan. Departemen Kehutanan. Jakarta I : 115-129.

Iyai DA \& Pattiselanno F. 2006. Diversitas dan Ekologi Biawak (Varanus indicus) di Pulau Pepaya Taman Nasional Teluk Cenderawasih, Irian Jaya Barat. Biodiversitas Vol. 7 (2), 181-186. DOI: 10.13057/biodiv/d070219.

Kameray, SB. 2013. Jenis-jenis Pandanus dan Freycinetia berdasarkan karakter morfologi dan anatomi di pulau Roswar, kabupaten Teluk Wondama. [Skripsi]. Sarjana Kehutanan. Fakultas Kehutanan. Universitas Papua, Manokwari.

Marpaung DRAK, Pasaribu N, \& Aththorick TA. 2013. Taxonomic Study of Pandanus (Pandanaceae) in Swamp Area, Aceh Singkil. Jurnal Natural 13(2).

Purwanto Y \& Munawaroh E. 2010. Etnobotani Jenis-jenis Pandanaceae sebagai Bahan Pangan di Indonesia. Berk. Penel. Hayati 5(A) :97-108.

Rahayu M, Sunarti S, \& Keim AP. 2008. Kajian Etnobotani Pandan Samak (Pandanus odoratissimus L.f.): Pemanfaatan dan Peranannya dalam Usaha Menunjang Penghasilan Keluarga di Ujung Kulon, Banten. Biodiversitas 9(4): 310-314. DOI: 10.13057.biodiv/d090415.

Rahayu SE \& Handayani S. 2008. Keanekaragaman Morfologi dan Anatomi Pandanus (Pandanaceae) di Jawa Barat.

Stone BC. 1982. New Guinea Pandanaceae: First approach to Ecology and Biogeography. Dalam: Gressit, J.L. (ed). Biogeography and ecology of new Guinea. Dr. W. Junk Publisher. The Hague. Monographiae Biologicae 42: 401-436.

Susiarti S, Djarwaningsih T, \& Keim AP. 2013 Pandan (Pandanaceae) in Flores Island, East Nusa Tenggara, Indonesia: An Economic-Botanical Study. Reinwardtia 13(5): 433-439.

Zebua LI, Supriatna J, \& Chikmawati T. 2009. Diversity of Red Fruit Pandan (Pandanus conideus Lam) In Papua, Indonesia . [Poster], at the International Seminar the $2^{\text {nd. }}$ Joint Seminar UI-FTS UKM at Bangi Campus, Malyasia, June, 22-23, 2009. 